\title{
Preferência e caracterização química de doce tipo ambrosia com ovos de galinha e de codorna
}

\author{
[Preference and chemical characterization of "doce de ambrosia" with chicken and quail eggs]
}

\section{"Comunicação Breve/Short Communication"}

\author{
Suelen Nunes da Silva ${ }^{1 *}$, Juliana Forgiarini ${ }^{1}$, Victor Fernando Büttow.Roll ${ }^{2}$, \\ Eduardo Gonçalves Xavier², Márcia Arocha Gularte ${ }^{3}$
}

\begin{abstract}
${ }^{1}$ Programa de Pós-Graduação em Zootecnia, Universidade Federal de Pelotas, Pelotas-RS, Brasil. ${ }^{2}$ Departamento de Zootecnia, Universidade Federal de Pelotas, Pelotas-RS, Brasil.

${ }^{3}$ Centro de Ciências Químicas, Farmacêuticas e de Alimentos, Universidade Federal de Pelotas, Pelotas-RS, Brasil.

*Autor para correspondência/Corresponding author: E-mail: suelennunesdasilva@ hotmail.com
\end{abstract}

\section{Resumo}

Objetivou-se com este trabalho caracterizar a composição química, a preferência e a intenção de compra de doces de ambrosia elaborados com ovos de galinha e de codorna. Foram realizadas análises bromatológicas (matéria seca, cinzas, proteína bruta e extrato etéreo), análises sensoriais com 50 consumidores; análise de preferência (escala variando de 7 - gostei extremamente a 1 - desgostei extremamente) e análise de intenção de compra (variando de 1 - só compraria se fosse forçado a 5 - compraria muito frequentemente) das ambrosias testadas. A partir da avaliação bromatológica foi verificado que a ambrosia elaborada com ovos de codorna apresentou maior teor de gordura $(\mathrm{p}<0,05)$ do que a elaborada com ovos de galinha. Na análise sensorial, no conjunto dos atributos avaliados, $68 \%$ dos consumidores preferiram ambrosia elaborada com ovos de codorna. De forma semelhante, $54 \%$ dos consumidores gostaram extremamente da ambrosia elaborada com ovos de codornas, enquanto que apenas $12 \%$ atribuíram este mesmo valor a ambrosia de ovos de galinha. Concluiu-se que ovos de codorna podem ser usados na elaboração de doce ambrosia, apresentando aceitação sensorial e potencial mercadológico. No entanto, ovos de codorna aumentam o teor de gordura da ambrosia em comparação com ovos de galinha.

Palavras-chave: atitude de compra; doce de ovos; sensorial.

\begin{abstract}
The objective of this work was to characterize the chemical composition, preference and the intention to buy "doce de ambrosia" made with chicken and quail eggs. Bromatological analyses (dry matter, ash, crude protein, and ethereal extract), sensorial analyses with 50 consumers, including preference analysis (scale ranging from 7 - extremely liked to 1 - extremely disagreeable) and purchase intention analysis (ranging from 1 - would only buy if forced 5 - would buy very often) of the ambrosias tested. From the bromatological evaluation, it was verified that ambrosia elaborated with quail eggs had a higher fat content $(p<0.05)$ than that made with chicken eggs. In sensory analysis, in the set of evaluated attributes, $68 \%$ of consumers preferred ambrosia made with quail eggs. Similarly, 54\% of consumers liked ambrosia made with quail eggs, while only $12 \%$ liked the ambrosia made with chicken eggs. It was concluded that quail eggs can be used in the elaboration of "doce de ambrosia", presenting sensory acceptance and market potential. However, quail eggs increase the fat content of ambrosia compared to chicken eggs.
\end{abstract}

Keywords: buying attitude; sweet egg; sensory.

O ovo é um alimento com elevado valor nutritivo, de fácil digestão e considerado pela Organização Mundial da Saúde (OMS) como um alimento de proteína padrão de alto valor biológico (Maia et al., 2014). É considerado um alimento acessível, prontamente disponível e, além das proteínas de alta qualidade, contém vitaminas e minerais essenciais, carotenoides, antioxidantes, luteína, zeaxantina, lecitina, colina e colesterol (Kovacs-Nolan et al., 2005). 
O ovo possui em sua composição aminoácidos essenciais em proporções adequadas, por isso é considerado uma proteína completa de alto valor biológico. Freitas et al. (2011) relataram que o aumento do consumo de ovos propicia benefícios nutricionais para a população. No entanto, a qualidade do produto ofertado ao consumidor é determinada por um conjunto de características que podem influenciar no seu grau de aceitabilidade e valor final do produto.

Em termos de caracterização física, o ovo de galinha pode ser dividido em três partes: a clara (59\%), a gema (31\%) e a casca (10\%) (Nys et al., 2011). Um ovo cru de tamanho médio (55 g) é constituído, segundo a Tabela da Composição dos Alimentos (INSA, 2010), por aproximadamente 41,4 g de água, 7,2 g de proteína e 5,9 de lipídios, o que se traduz em aproximadamente $82 \mathrm{kcal}$. Respeitando a proporcionalidade, não há grande diferença na composição física entre ovos de codornas e de galinha, mas a composição química apresenta algumas diferenças. O ovo de codorna, por exemplo, apresenta maiores teores de lipídeos e ácido ascórbico do que o ovo de galinha, além de uma maior concentração de ferro (TACO, 2011).

Assim como o ovo, o leite de vaca também é considerado um dos alimentos mais completos em virtude do elevado valor biológico, da alta digestibilidade e de constituir excelente fonte de proteína e cálcio (Revers et al., 2016). Por todos esses fatores e benefícios, os ovos, bem como o leite, estão presentes na dieta humana há muito tempo, sendo consumidos como uma refeição ou também utilizados como ingredientes de diversos pratos culinários.

A ambrosia contém esses dois ingredientes, leite e ovos, além de açúcar, e é muito apreciada na culinária brasileira. Introduzida no Brasil pelos colonizadores portugueses, a ambrosia tem origem na Grécia Antiga onde era considerada a "comida dos Deuses" e acreditava-se ter o poder de garantir a imortalidade aos que consumiam.

Diante do que foi apresentado, o experimento foi executado com o objetivo de observar se os ovos de codorna apresentam potencial para melhorar a elaboração do doce, ou pelo menos manter a aparência, a textura e o sabor característico da ambrosia produzida com ovos de galinha.

O experimento foi realizado no Laboratório de Análises Sensoriais e Instrumentais do Departamento de Zootecnia da Universidade Federal de Pelotas (UFPel), RS, Brasil.
Participaram do painel alunos, servidores docentes

e servidores técnico-administrativos da Universidade, convidados aleatoriamente, totalizando 50 consumidores.

Foram elaboradas duas preparações de ambrosia, uma com ovos de galinha (Tratamento 1 - T1) e outra com ovos de codorna (Tratamento 2 - T2). Para produzir as formulações foram utilizados oito ovos de galinha no T1 e 54 ovos de codorna no $\mathrm{T} 2$, totalizando $480 \mathrm{~g}$ de ovos em cada.

Os ovos foram adquiridos no comércio local e as ambrosias preparadas no dia anterior à realização da pesquisa. Em cada formulação, foram utilizados dois litros de leite UHT integral e $1 \mathrm{~kg}$ de açúcar cristal.

Os ovos foram batidos manualmente a fim de homogeneizar as gemas com as claras, aos quais foram adicionados o leite e o açúcar (10 colheres) e então colocados em panela de pressão (1 $1 \mathrm{~atm}) \mathrm{em}$ fogo brando por 40 minutos. Após este período, foi adicionado à mistura o restante do açúcar e deixada para ferver em panela sem pressão. Quinze minutos antes do final do processo, foram adicionadas oito unidades de cravo da índia em cada tipo de ambrosia. O preparo total durou 2 horas e 40 minutos.

No Laboratório de Nutrição Animal do Departamento de Zootecnia da UFPel foram realizadas análises bromatológicas das amostras dos doces. As análises foram realizadas de acordo com o método de Weende, todas em triplicata (AOAC, 1995).

As amostras passaram por pré-secagem em estufa a $55^{\circ} \mathrm{C}$, durante quatro dias e depois foram trituradas em multiprocessador. Foi realizada a análise de matéria seca em estufa a $105{ }^{\circ} \mathrm{C}$; a determinação de cinzas em forno mufla; o extrato etéreo em extrator de Soxhlet; e a proteína bruta através do método de Kjeldahl (AOAC, 1995).

A análise de sólidos solúveis totais das amostras foi realizada através de refratometria com o uso de refratômetro digital (marca Tecnal, modelo AR/200) (Lutz, 1985). Essa análise foi expressa em graus Brix e refere-se à porcentagem, em peso, de sacarose em solução a $20^{\circ} \mathrm{C}$.

As amostras de doce de ambrosia feitas com ovos de galinha e com ovos de codorna foram avaliadas por 50 consumidores, selecionados ao acaso no campus da Universidade Federal de Pelotas. Ao serem abordados, os consumidores foram informados sobre o tipo de doce a ser consumido e perguntados sobre alergias, intolerâncias ou restrições alimentares, além disso 
leram e assinaram o Termo de Consentimento Livre e Esclarecido (TCLE).

No Laboratório de Análises Sensoriais e Instrumentais foi realizado o teste de comparação pareada, em que foi solicitado aos consumidores que as avaliassem da esquerda para a direita e que marcassem um ' $\mathrm{X}$ ' no código daquela ambrosia de sua preferência, para os seguintes atributos: cor, odor, sabor característico de ovo, sabor característico, textura granulosa e preferência geral. As amostras foram codificadas com um número aleatório de três dígitos e apresentadas simultaneamente ao consumidor, sob luz branca e em cabines individuais. Junto a cada amostra servida, o consumidor recebeu um copo de água à temperatura ambiente, para limpar o palato entre uma amostra e outra. No momento da avaliação, os consumidores responderam a duas questões estruturadas em escala hedônica. Uma sobre preferência de ambrosia, em que foi solicitado aos consumidores que assinalassem uma nota para cada tipo de ambrosia em escala variando de 7 (gostei extremamente) a 1 (desgostei extremamente), e outra referente à atitude de compra (FACT de 5 pontos) variando de 1 (só compraria se fosse forçado) a 5 (compraria muito frequentemente). Ainda foi calculado o índice de aceitabilidade, onde a nota 7 é a média máxima e com regra de três simples comparado com a média de cada amostra, expresso em percentual.

Para as variáveis sensoriais os dados foram submetidos à estatística descritiva e resumidos em gráficos de frequência relativa. Para a comparação das médias das variáveis bromatológicas e de preferência e atitude de compra do consumidor foi utilizado o Teste $t$ de Student ao nível de significância 5\%, utilizando-se o programa Statistica $^{\circledR} 6.0$ (Statsoft, 2001).

Dos 50 consumidores que participaram do teste, $70 \%$ eram mulheres, $28 \%$ homens ( $2 \%$ não declarados). Noventa e seis por cento dos consumidores tinham idades entre 19 e 50 anos, os demais tinham mais de 50 anos. Quanto à frequência de consumo, $90 \%$ disseram consumir ocasionalmente este doce.

$\mathrm{Na}$ Tabela 1 estão apresentados os resultados obtidos na análise bromatológica das ambrosias. Houve diferença significativa entre os tratamentos $(p<0,05)$ apenas na variável extrato etéreo, em que a ambrosia feita com ovos de codorna apresentou maior teor. Possivelmente estes resultados podem ser explicados pelo maior teor de lipídeos nos ovos de codorna em comparação com os ovos de galinhas conforme consta na Taco (2011).

Pinheiro e Penna (2008) relatam que a gordura confere sabor e cremosidade aos alimentos sendo, portanto, muito importante em termos sensoriais. Isso possivelmente explica a maior preferência dos consumidores pela ambrosia de ovos de codorna, tendo em vista que a mesma apresentava maior quantidade de extrato etéreo (Tabela 2).

Tabela 1. Médias, em porcentagem, e desvio padrão de análises bromatológicas de ambrosias elaboradas com ovos de galinha e ovos de codorna, em base seca.

\begin{tabular}{ccccc}
\hline Ambrosias & Matéria seca & Cinzas & Extrato etéreo & Proteína \\
\hline T1 - Com ovos de galinha & $75,11( \pm 2,40)$ & $0,91( \pm 0,32)$ & $12,23( \pm 0,37)$ & $7,69( \pm 0,18)$ \\
T2 - Com ovos de codorna & $74,17( \pm 1,44)$ & $1,12( \pm 0,01)$ & $14,85( \pm 0,29)^{*}$ & $8,04( \pm 0,49)$ \\
\hline p & 0,5992 & 0,3692 & $<0,001$ & 0,3316 \\
\hline
\end{tabular}

*Médias diferem na coluna pelo teste 't' $(\mathrm{p}<0,05)$.

Tabela 2. Médias e desvio padrão de preferência da escala hedônica (notas de 1 a 7) e atitude de compra (notas de 1 a 5) de diferentes tipos de ambrosias com ovos de galinha e de codorna.

\begin{tabular}{ccc}
\hline Ambrosia & Preferência & Atitude de Compra \\
\hline T1 - Com ovos de galinha & $5,3( \pm 0,9)$ & $3,9( \pm 0,9)$ \\
T2 - Com ovos de codorna & $6,4( \pm 0,7)^{*}$ & $4,2( \pm 0,7)$ \\
\hline
\end{tabular}

*Médias diferem na coluna pelo teste ' $\mathrm{t}$ ' $(\mathrm{p}<0,05)$.

Salienta-se que embora a ambrosia com os ovos de codorna tenha apresentado maior quantidade de lipídeos, isso não significa necessariamente que ela contenha maior teor de colesterol. Bragagnalo e Rodriguez-Amaya (2003) mensuraram o teor de colesterol de ovos de galinha e de codornas e não obtiveram diferença significativa entre as espécies $(12,0$ e $12,1 \mathrm{mg} / \mathrm{g}$, respectivamente). 
Ainda no intuito de justificar a preferência pela ambrosia feita com ovos de codorna, foi realizada a análise de sólidos solúveis totais das amostras através de refratometria, expressa em graus Brix, que determinou qual das amostras é mais doce. A ambrosia com ovos de codorna apresentou maior valor de sólidos solúveis totais (55 graus Brix) comparado com ovos de galinha (40 graus Brix).

Tendo em vista o fato de que foram usados números de ovos diferentes para cada preparo (oito ovos de galinha e 54 ovos de codorna), é possível que as proporções gema/clara tenham sido diferentes também. A gema concentra a maior quantidade de carboidratos totais do ovo e o ovo de codorna, por sua vez, apresenta em torno de $60 \%$ mais carboidratos que o ovo de galinha (TBCA, 2017), o que pode explicar a resposta encontrada na análise de sólidos solúveis totais (Graus Brix), encontrada deste experimento.

Conforme a Tabela Brasileira de Composição de Alimentos (TBCA, 2017), ovos de codorna são ricos em proteína (13,1 g contra $10,4 \mathrm{~g}$ do ovo de galinha), ferro (3,35 mg contra $1,34 \mathrm{mg}$ do ovo de galinha), vitaminas $\mathrm{B}_{1}$ e $\mathrm{B}_{12}$, contendo $0,11 \mathrm{mg}$ e $1,63 \mathrm{mg}$ dessas vitaminas, contra 0,07 $\mathrm{mg}$ e $0,94 \mathrm{mg}$ do ovo de galinha. Todos esses atributos tornam um alimento preparado com ovos de codorna mais rico em nutrientes.

$\mathrm{Na}$ Figura 1 estão apresentadas as frequências de cada atributo sensorial. Para os atributos 'sabor característico de ovo' e 'textura granulosa' $62 \%$ dos consumidores preferiram a ambrosia com ovos de galinha. Para os atributos: cor $(76 \%)$, odor $(74 \%)$, sabor característico $(74 \%)$ e preferência geral (68\%) os consumidores assinalaram preferencialmente a ambrosia com ovos de codorna.

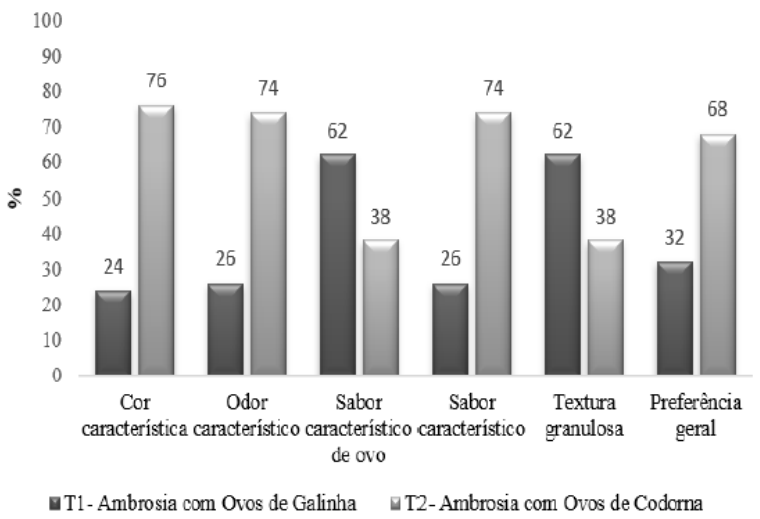

Figura 1. Frequência dos atributos sensoriais de ambrosia com ovos de galinha e com ovos de codorna.
Os dados de preferência das ambrosias estão apresentados na Figura 2. Um total de $44 \%$ dos consumidores gostou ligeiramente da ambrosia com ovos de galinha (nota 5), enquanto que 54\% dos consumidores gostaram extremamente da ambrosia com ovos de codorna (nota 7), sendo assim a preferida pelos consumidores. Esses dados foram comparados pelo índice de aceitabilidade, que para o doce de ambrosia com ovos de codorna foi $91 \%$ e o doce com ovos de galinha foi $76 \%$.

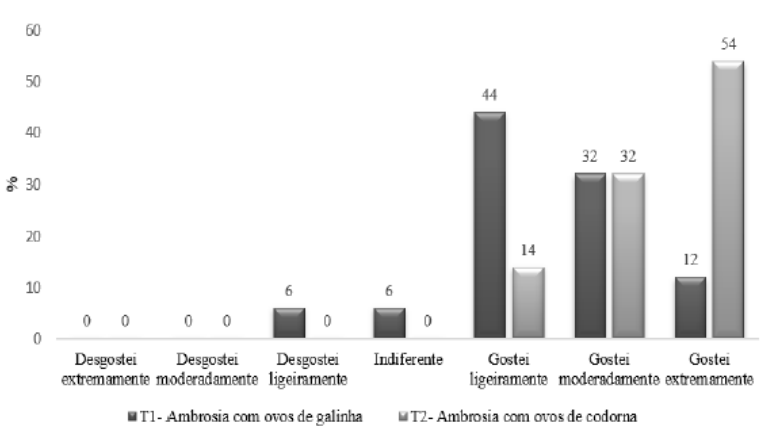

Figura 2. Frequência da preferência através da escala hedônica de cada tipo de ambrosia, com ovos de galinha e de codorna.

Na Figura 3 estão apresentados os dados em porcentagem da escala estruturada para a atitude de compra. Observa-se que $56 \%$ dos consumidores comprariam de vez em quando a ambrosia com ovos de galinha. Já para a ambrosia com ovos de codorna, 38\% comprariam de vez em quando e $44 \%$ comprariam muito frequentemente. Isto comprova os dados de preferência geral, demonstrados na Figura 1.

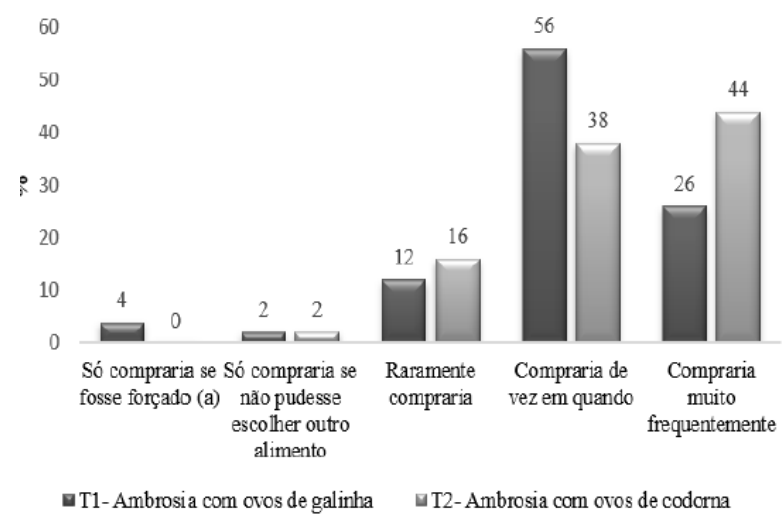

Figura 3. Frequência de intenção de compra de cada tipo de ambrosia, com ovos de galinha e de codorna.

No teste de preferência (Tabela 2), foi observado que os consumidores preferiram a ambrosia com ovos de codorna. Entre as razões apontadas pela maior preferência destaca-se o fato de ser considerada mais doce (sendo que a 
quantidade dos ingredientes e o tempo de preparo foram iguais para ambas, mudando apenas a origem do ovo). Na escala hedônica, a ambrosia elaborada com ovos de codorna foi pontuada principalmente na escala gostei regularmente a extremamente. Já para a atitude de compra não foi encontrada diferença significativa entre as ambrosias.

Concluiu-se que ovos de codorna podem ser usados na elaboração de doce ambrosia, apresentando aceitação sensorial e potencial mercadológico. No entanto, ovos de codorna aumentam o teor de gordura da ambrosia em comparação com ovos de galinha.

\section{Conflito de Interesse}

Os autores declaram não existir conflito de interesse.

\section{Comitê de Ética}

$\mathrm{O}$ presente estudo não necessitou da submissão ao Comitê de Ética, pois foi feito com o consentimento prévio dos participantes, que foram alertados sobre os ingredientes contidos nos doces, podendo escolher participar ou não das degustações, além de lerem e assinarem o TCLE.

\section{Referências}

AOAC. Official Methods of Analysis of the AOAC international. Método ${ }^{\circ}$ 970.12. Association of Official Analytical Chemists International. $16^{\text {th }}$ ed. Washington, 1995.

Bragagnalo, N.; Rodriguez-Amaya, D.B. Comparison of the cholesterol content of Brazilian chicken and quail eggs. Journal of Food Composition and Analysis, 16(1): 147153, 2003.

Freitas, L.W.; Paz, I.C.L.A.; Garcia, R.G.; Caldara, F.R.; Seno, L.O.; Felix, G.A.; Lima, N.D.S.; Ferreira, V.M.O.S.; Cavichiolo, F. Aspectos qualitativos de ovos comerciais submetidos a diferentes condições de armazenamento. Revista Agrarian, 4(11): 66-72, 2011.

INSA. Instituto Nacional de Saúde. Tabela da composição dos alimentos portuguesa- Ovo (de galinha) inteiro cru. 2010. Disponível em:
<http://www.insa.pt/sites/INSA/Portugues/Ar easCientificas/AlimentNutricao/AplicacoesO nline/TabelaAlimentos/PesquisaOnline/Pagin as/DetalheAlimento.aspx?ID=I S083>. Acesso em: 24 out. 2017.

Kovacs-Nolan, J.; Phillips, M.; Mine, Y. Avanço no valor dos ovos e dos componentes do ovo para a saúde humana. Journal of Agriculturaland Food Chemistry, 53(1): 8421-8431, 2005.

Lutz, I.A. Métodos químicos para análise de alimentos. Procedimentos e determinações gerais. $3^{\mathrm{a}}$ ed. São Paulo: Instituto Adolfo Lutz, 1985. Capítulo IV.

Maia, R.C.; Tavernari, F.C.; Albino, L.F.T.; Petrolli, T.G.; Barros, V.R.S.M.; Carvalho, B.R. Formação e qualidade dos ovos. In: Albino, L.F.T.; Carvalho, B.R.; Maia, R.C.; Barros, V.R.S.M. Galinhas poedeiras: criação e alimentação. $1^{\text {a }}$ ed. Viçosa: Aprenda Fácil, 2014. p. 272-345.

Nys, Y.; Bain, M.; Immerseel, F.V. Egg chemistry, production, and consumption. In: Improving the safety and quality of eggs and egg products. Cambridge: Woodhead Publishing Limited, 2011. p.64-65.

Pinheiro, M.V.S.; Penna, A.L.B. Substitutos de gordura: tipos e aplicações em produtos lácteos. Alimentos e Nutrição, 15(2): 175186, 2008.

Revers, L.M.; Danielli, A.J.; Iltchenco, S.; Zeni, J.; Steffens, C.; Steffens, J. Obtenção e caracterização de iogurtes elaborados com leites de ovelha e de vaca. Revista Ceres, 63(6): 747-753, 2016.

Statsoft, I.N.C. Statistica (Data Analysis Software System), version 6. Tulsa, USA, v. 150, 2001.

TACO. Universidade Estadual de Campinas. Tabela Brasileira de Composição de Alimentos. 2011. Disponível em: <http://www.cfn.org.br>. Acesso em: 24 out. 2017.

TBCA. Universidade de São Paulo. Tabela Brasileira de Composição de Alimentos. Versão 6.0. São Paulo, 2017. Disponível em: <http://www.fcf.usp.br/tbca/>. Acesso em: 24 out. 2017. 